\title{
Techno-Economic Analysis of Power-to-Heat Systems
}

\author{
Alberto Vannoni ${ }^{1}$, Alessandro Sorce ${ }^{1 *}$,Alberto Traverso ${ }^{1,}$,Aristide Fausto Massardo ${ }^{1}$ \\ ${ }^{1}$ Thermochemical Power Group, University of Genoa, Via Montallegro 1, 16145 Genoa, Italy
}

\begin{abstract}
The heating and cooling sector, responsible for a large fraction of greenhouse emissions, may have a large scale impact on the energy system evolution contributing to smart industrial and domestic electrification; at the same time the recent increase of renewable energy sources installation, posing a threat in terms of grid stability, makes available a considerable amount of clean and cheap electrical energy during peak hours production. Power to heat technologies constitute a promising solution to face both these issues reducing the electric demand variability and decarbonizing the heat production. Large vapor compression heat pumps are a reliable technology able to compete, under the economic point of view, with the heat-onlyboilers in order to serve district heating networks. Performance and economic profitability of a compression cycle is strongly dependent on available thermal source and the temperature of water delivered to the network. The present work explores and compares performance and economic indicators under different installation conditions, considering compression heat pumps employing four different fluids: a traditional HCF (R134a) and three natural fluids, ammonia (R717), butane (R600), and propane (R290), often preferred nowadays to HCFs due to the lower global warming potential.
\end{abstract}

\section{Introduction}

The use of large size Heat Pump, HP, in Europe as generators of District Heating, DH, dates back to the 1980s, when they were exploited in Sweden to balance newly installed nuclear capacity. Today the adoption of such technology is driven by the need to balance Renewable Energy Sources, RES, acting as a power- toheat solution, connecting thermal and electricity grids, with efficiency higher than an electrical boiler, competing with power to gas solutions [1]

Moreover, the substitution of fossil fuel Heat Only Boilers, HOBs, with HPs can eliminate the pollutant associated with the combustion process and the $\mathrm{CO}_{2}$ emissions. With the heating and cooling sector using half of the total energy consumed in Europe [2], the HP technology was estimate to supply the $25-30 \%$ of the total DH production in 2050 [3], with a subsequent reduction of the global greenhouse gas emission impact from fossil fuelled combustion plants.

On the other side, the adoption in the HPs cycles of refrigerants with low environmental impact, is becoming mandatory: the so-called "natural refrigerants" characterized by very low global warming potential (GWP) and null Ozone Depletion Potential, ODP are more often adopted in the new installations instead of HFCs and have found a new application within the Organic Rankine Cycle [4].

A. David et al., presented a survey of the existing capacity of electric large-scale heat, highlighting as most of the new projects, that were commissioned after 2006, registered an increase of the use of natural refrigerants, about the $20 \%$ of their survey data base [5].

Viable options for natural fluids are some hydrocarbons, ammonia, and carbon dioxide; however, flammability, toxicity, corrosive properties, and highpressure requirement must be considered in the design phase [6]. HPs with hydrocarbons and ammonia are considered commercially available, with performance similar to a heat pump using HFCs, while carbon dioxide are still at lower Technology Readiness Level [7] and will be not addressed in this work.

Up to 2017, the R134a was the most used HFC [5], since it is non-flammable, non-toxic, with a zero ODP, but due to its GWP potential of 1430, it was prohibited already in countries such as Denmark and Switzerland, and included on the list of controlled substances to be phased down through the Montreal Protocol by 2040. Ammonia, R717, widely adopted for industrial refrigeration (i.e. large scale equipment with high efficiencies) is suitable for the largest plants reaching up to around $73{ }^{\circ} \mathrm{C}$ using standard components and up to $90{ }^{\circ} \mathrm{C}$ utilizing special components for high pressure

\footnotetext{
* Corresponding author: alessandro.sorce@unige.it
} 
levels [7]. However, the new commissioned units have a lower capacity with respect to the R134a ones, as presented in table 1.

Hydrocarbons are primarily used in medium sized applications where either propane or isobutane is used as refrigerant [7]. Propane, R290, can reach temperatures of $65^{\circ} \mathrm{C}$ whereas isobutene, R600a, can reach temperatures of around $85^{\circ} \mathrm{C}$. Moreover, butane, $\mathrm{R} 600$, has the capability to extend even further the maximum supply temperature thanks to its higher critical temperature.

\section{Thermal Sources and Supply Conditions}

This section presents the historical installation conditions and the scenarios considered for the TechnoEconomic Analysis, TEA. The most common heat source is wastewater, followed by ambient water (i.e. sea, lake and river water). Those sources were clustered in table 1 as "water" with also geothermal water due to the high availability of the resource with respect to HP size. Geothermal water presents the higher available temperature (average around $35^{\circ} \mathrm{C}$ ) and a maximum of $55^{\circ} \mathrm{C}$.

Waste Heat, including flue gas and industrial waste heat source, has a maximum temperature of $40^{\circ} \mathrm{C}$, even if higher temperature can be exploited [8].

No air Large Size Heat Pump was registered so far.

Table 1. Large-Scale Electric Heat Pumps by Source [3].

\begin{tabular}{|c|c|c|c|c|c|}
\hline \multirow{2}{*}{\multicolumn{2}{|c|}{$\begin{array}{c}\text { Heat Sources } \\
\text { Refrigerant }\end{array}$}} & \multicolumn{2}{|c|}{ Water } & \multicolumn{2}{|c|}{ Waste Heat } \\
\hline & & \multirow{2}{*}{$\frac{\mathrm{R} 717}{14}$} & \multirow{2}{*}{$\frac{\mathrm{R}-134 \mathrm{a}}{64}$} & \multirow{2}{*}{$\frac{\mathrm{R} 717}{12}$} & \multirow{2}{*}{$\frac{\mathrm{R}-134 \mathrm{a}}{12}$} \\
\hline Units [\#] & & & & & \\
\hline \multirow{3}{*}{$\begin{array}{c}\text { Unit } \\
\text { Capacity } \\
\text { [MW] }\end{array}$} & $\min$ & 1.2 & 0.8 & 1 & 1.5 \\
\hline & avg & 2.45 & 14.8 & 1.5 & 9.3 \\
\hline & $\max$ & 4.4 & 50 & 3 & 17 \\
\hline \multirow{3}{*}{$\begin{array}{c}\text { T source } \\
{\left[{ }^{\circ} \mathrm{C}\right]}\end{array}$} & $\min$ & 0 & 3 & 18 & 12 \\
\hline & avg & 10.7 & 15.5 & 31 & 31 \\
\hline & $\max$ & 25 & 55 & 40 & 38 \\
\hline \multirow{3}{*}{$\begin{array}{c}\text { T supply } \\
{\left[{ }^{\circ} \mathrm{C}\right]}\end{array}$} & $\min$ & 43 & 55 & 60 & 70 \\
\hline & avg & 71.7 & 78.0 & 68 & 79.1 \\
\hline & $\max$ & 90 & 90 & 81 & 90 \\
\hline \multirow{3}{*}{$\begin{array}{c}\text { COP } \\
{[-]}\end{array}$} & $\min$ & 2.85 & 2.65 & 3.9 & 3.1 \\
\hline & avg & 3.8 & 3.15 & 4.86 & 4.1 \\
\hline & $\max$ & 5.5 & 6 & 6.5 & 5.4 \\
\hline $\mathrm{COP}$ & $\min$ & 48.7 & 36.6 & 32.6 & 39.5 \\
\hline \multirow{2}{*}{$\begin{array}{c}\frac{\mathrm{COP}}{\mathrm{COP}_{\text {id }}} \\
{[\%]}\end{array}$} & avg & 67.5 & 55.2 & 51.0 & 57.9 \\
\hline & $\max$ & 85.5 & 75.6 & 69.2 & 75.9 \\
\hline
\end{tabular}

The registered maximum supply temperature was around $90^{\circ} \mathrm{C}$ for all the fluids, with the average for $\mathrm{R} 134 \mathrm{a}$ around $80^{\circ} \mathrm{C}$ and for $\mathrm{R} 717$ around $70^{\circ} \mathrm{C}$. Since ammonia-based installations are more recent, this is coherent with the general trend of reducing maximum DH systems supply temperature.

On the performance side, the declared Coefficient of Performance, COP, was benchmarked against the ideal COP, calculated as in the Carnot approach:

$$
C O P_{i d}=\left(T_{\text {supply }}+273.15\right) /\left(T_{\text {supply }}-T_{\text {source }}\right)
$$

The resulting performance indicator, $\mathrm{COP} / \mathrm{COP}_{\mathrm{id}}$, presents soundly values with an average of $54,7 \%$ for all the installation condition except for the water-R717 that shows better performance $(67.5 \%)$ confirmed also by the shift in the maximum and minimum value. This figure is influenced by design choices (e.g. the components selection and cycle design parameters). The observed shift is probably due to absolute COP design requirements (for efficiency and market constraints) despite the lower source of temperatures available.

For the TEA, the following scenarios were considered, as for table 2. The temperature drop in the source side, $\Delta T_{\text {source }}$, was set on the base of the resource mass flow rate availability, considering for the waste heat, more scenarios of resource exploitation.

Table 2. Scenarios for the Techno-Economic Analysis

\begin{tabular}{|c|c|c|c|}
\hline $\begin{array}{c}\text { Heat } \\
\text { Sources }\end{array}$ & $T_{\text {source }}\left[{ }^{\circ} \mathrm{C}\right]$ & $\Delta T_{\text {source }}[\mathrm{K}]$ & $\begin{array}{c}\text { Evaporator } \\
\text { Heat } \\
\text { Exchanger }\end{array}$ \\
\hline $\begin{array}{c}\text { Waste } \\
\text { Heat }\end{array}$ & 4070100 & 10203040 & $\begin{array}{c}\text { Plate and } \\
\text { Frame }\end{array}$ \\
\hline Water & 010203555 & 10 & Shell \& Tube \\
\hline Air & -1001020 & 10 & $\begin{array}{c}\text { Finned fan- } \\
\text { cooled }\end{array}$ \\
\hline
\end{tabular}

On the DH side, the different generation of waterbased $\mathrm{DH}$ networks are usually divided as: $2^{\text {nd }} \mathrm{G}$ : $T_{\text {supply }}>100 ; 3^{\text {rd }} \mathrm{G} 70<T_{\text {supply }}<100 ; 4^{\text {th }} \mathrm{G} T_{\text {supply }}<70^{\circ} \mathrm{C}$ [9]

The difference between supply and return temperature of the DH was calculated, as:

$$
\Delta T_{\text {supply }}=10+T_{\text {supply }} / 3
$$

The fluid driving the heat pump could affect significantly the techno-economic performances. The present analysis considers three fluid presenting reduced environmental impact: Ammonia (R717) and two hydrocarbon fluid butane(R600) and propane (R290), whose performances are benchmarked against the standard R134a, today avoided because of its high Global Warming Potential.

Table 3. Fluids characteristics

\begin{tabular}{|c|c|c|c|c|}
\hline & R134a & R717 & R600 & R290 \\
\hline GWP & 1430 & 0 & 3 & 3 \\
\hline ODP & $1.5 \mathrm{E}-05$ & 0 & 0 & 0 \\
\hline $\mathrm{p}_{\text {crit }}[$ bar $]$ & 40.6 & 113.3 & 38.0 & 42.5 \\
\hline $\mathrm{T}_{\text {crit }}\left[{ }^{\circ} \mathrm{C}\right]$ & 101.1 & 132.3 & 152.0 & 96.7 \\
\hline
\end{tabular}




\section{Techno-Economic Model}

The TEA has been carried out on a vapor compression heat pump cycle driven by a volumetric compressor, schematized in Figure 1, the cycle includes a regenerative heat exchange in order to preheat the vapor entering the compressor and cooling the liquid before it expands. The model, developed in Matlab, selects the pressure within the cycle such that the Coefficient of Performance, COP, is maximized for the given temperature levels. Table 4 reports all the model assumptions the: it should be highlighted that pressure drops in piping and in the heat exchangers have been neglected.

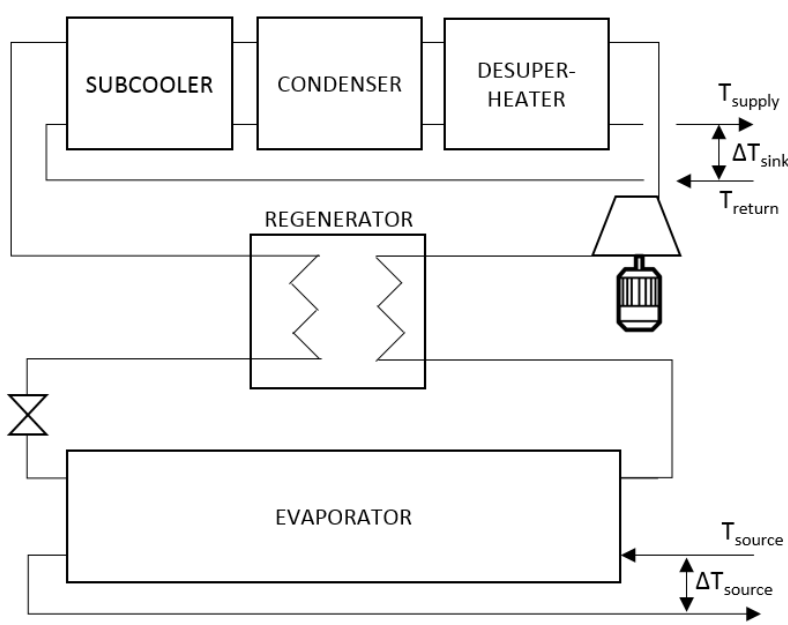

Fig. 1. Scheme of the Heat Pump considered for the Techno-Economic Analysis

Table 4. Heat pump modelling assumptions

\begin{tabular}{|c|c|c|c|c|}
\hline & $\begin{array}{c}\text { Cost } \\
\text { Fuction }\end{array}$ & $\eta_{\mathrm{vol}}$ & $\eta_{\text {isoentropic }}$ & $\boldsymbol{\eta}_{\text {motor }}$ \\
\hline \multirow[t]{2}{*}{ Compressor } & [10] & 0.8 & 0.8 & 0.95 \\
\hline & & $\Delta \mathbf{T}_{\text {pinch }}$ & $\mathbf{U}\left[\mathbf{W} / \mathbf{m}^{2} \mathbf{K}\right]$ & $\Delta \mathbf{T}_{\mathrm{SH}}$ \\
\hline Evaporator & $\begin{array}{l}{[11]} \\
{[12]} \\
{[10]}\end{array}$ & $5 \mathrm{~K}$ & $\begin{array}{|lr|}\text { Finned: } & 300 \\
\text { S\&T: } & 600 \\
\text { Chevron: } & 2500 \\
\end{array}$ & \\
\hline Condenser & \multirow{4}{*}[10]{} & $5 \mathrm{~K}$ & 2500 & \\
\hline Subcooler & & $7 \mathrm{~K}$ & 2850 & \\
\hline DSH & & $5 \mathrm{~K}$ & 350 & \\
\hline Regenerator & & $5 \mathrm{~K}$ & 50 & $10 \mathrm{~K}$ \\
\hline
\end{tabular}

The fluid thermodynamic properties calculation is based on the CoolProp libraries [13]. Then each component can be sized basing on capacity required by each heat exchanger and the volumetric flow rate through the compressor. While the evaporator heat exchanger is selected based on the heat source, according to table 2, the other heat exchangers are supposed to be Chevron type, the maximum acceptable pressure in the cycle is fixed at 50bar for R717 and 28bar for R134a, R600 and R290 [10]. Temperature is also limited at the compressor discharge to $180^{\circ} \mathrm{C}$ in order to avoid oil degradation. In the air-sourced HP scenario, a fan is needed to force the convection at the finned evaporator heat exchanger. The fan parasitic consumption is estimated assuming on the air side an average pressure drop of 5.5 mbar.

The economic evaluation of the heat pumps was based on the economic method presented by Bejan et al. [14], where individual component Purchased Equipment Cost, PEC, are used to account for the overall Total Capital Investment (TCI). The heat pump TCI was calculated as 4.16 [14] higher than the PEC of all the components. This was done to account for additional costs related to new investment at an existing facility. The components cost functions are specific for the fluids analysed [10].

In order to estimate the profitability, the difference in net present value between the heat pump and a natural gas fired Heat Only Boiler, HOB, working in the same condition, was assessed:

$\triangle N P V=N P V_{H P}-N P V_{H O B}$

Where the NPV for the system $\mathrm{j}$ is computed as:

$$
N P V_{j}=-T C I_{j}+\sum_{k=1}^{n} \frac{-V C_{j}-O \& M_{j}}{\left(1+i_{e f f}\right)^{k}}
$$

All variables in equation 4 are negative because, in order to assess the difference in profitability, only costs have been considered, since revenue are common to both systems: in fact, the comparison is made for identical thermal outputs. In this way it is possible to proceed with a fair comparison avoiding specific assumptions on the revenues. TCI is assumed to be zero for the HOB since it was considered as already existing. The Operating and Maintenance costs are composed by a fixed part, 1900 $€ / M W y r$ for the HOB and $2000 € / M W y r$ for the HP, and a variable component, $1 € / \mathrm{MWh}$ for the $\mathrm{HOB}$ and computed as it follows for the HP [7].

$$
2.7509+7 \cdot 10^{-5}(\text { Capacity }[k W])[€ / \mathrm{MWh}]
$$

$\mathrm{i}_{\mathrm{eff}}$ is the effective interest rate over the lifetime of the system, calculated as below, where $\mathrm{i}$ is the interest rate and $i_{L}$ is the inflation rate, assumed equal to $7 \%$ and $2 \%$ respectively on a time horizon of 20 years ( $n$ in eq. 4 ).

$$
i_{e f f}=\frac{1+i}{1+i_{L}}-1
$$

The other variable cost, $\mathrm{VC}$, i.e. the fuel and electricity consumption, depend on the efficiency of the two systems. In the HOB case the fuel cost includes also the price of $\mathrm{CO}_{2}$ emission allowance in the EU-ETS.

$$
\begin{aligned}
& V C_{H P}=\frac{\dot{Q}}{C O P} C_{e l} h \\
& V C_{H O B}=\frac{\dot{Q}}{\eta_{H O B}}\left(C_{g a s}+E \cdot C_{\mathrm{CO}_{2}}\right) h
\end{aligned}
$$

The cost of gas and electricity are assumed equal to the EU27 average for the second semester 2019 including all taxes and levies, $0.1508 € / \mathrm{kWh}$ for electricity and $0.0413 € / \mathrm{kWh}$ for gas, fitting the bands consumption with a power function [15], the emission factor $E$ is equal to 0.2014 ton/MWh according to the Italian government data for natural gas [16], while $C_{\mathrm{CO}_{2}}$ mean value on the plant's life time is assumed to be $40 € /$ ton considering the current value and the foreseen grow rate 
$[17,18]$ The Heat boiler efficiency has been modelled according to Satyavada and Baldi in order to take into

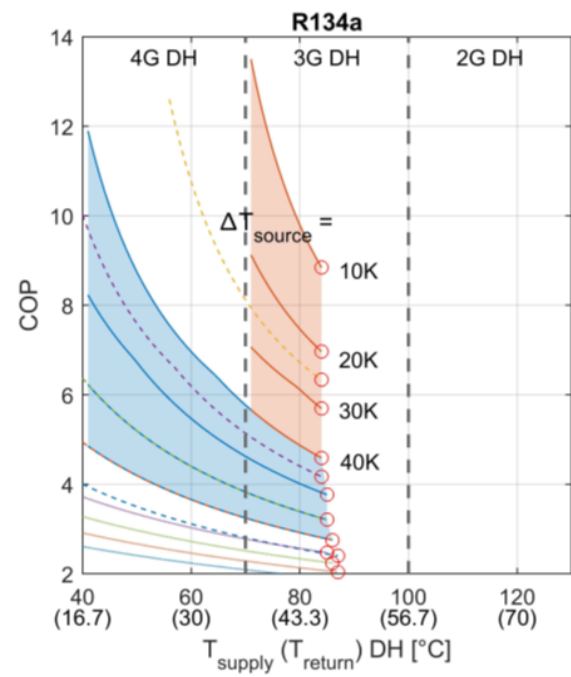

(a)

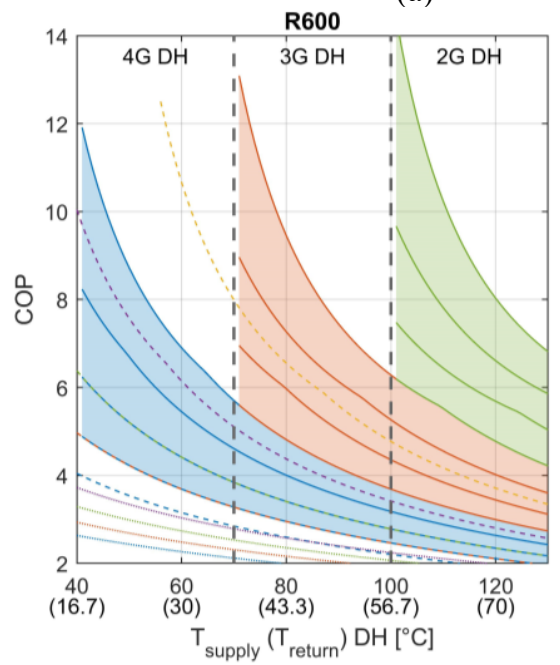

(c)
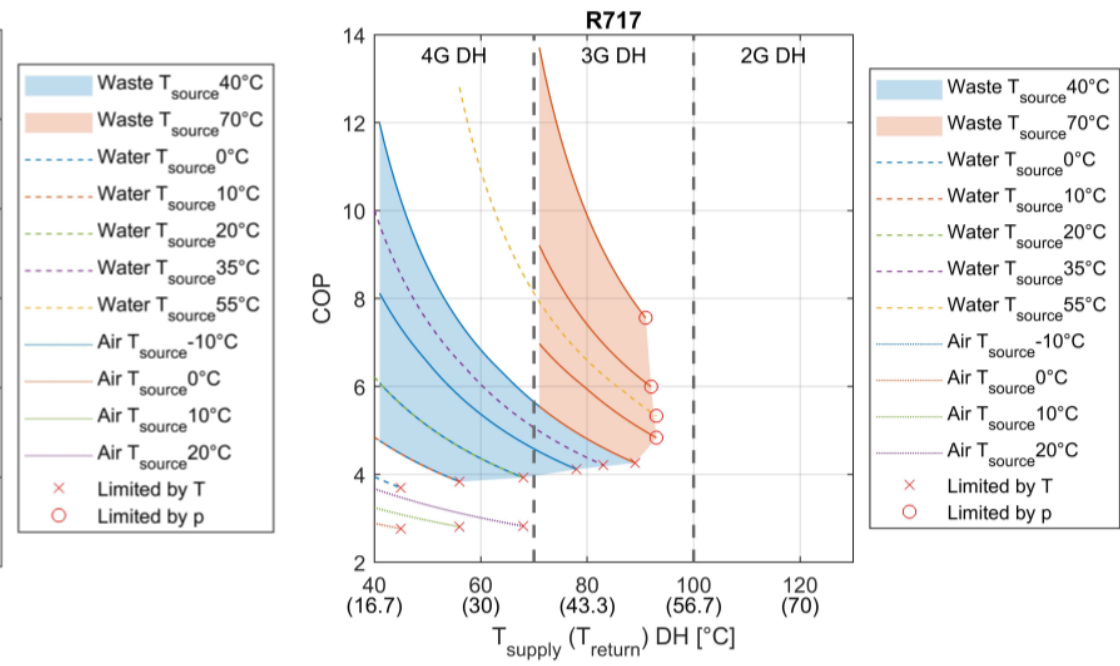

(b)
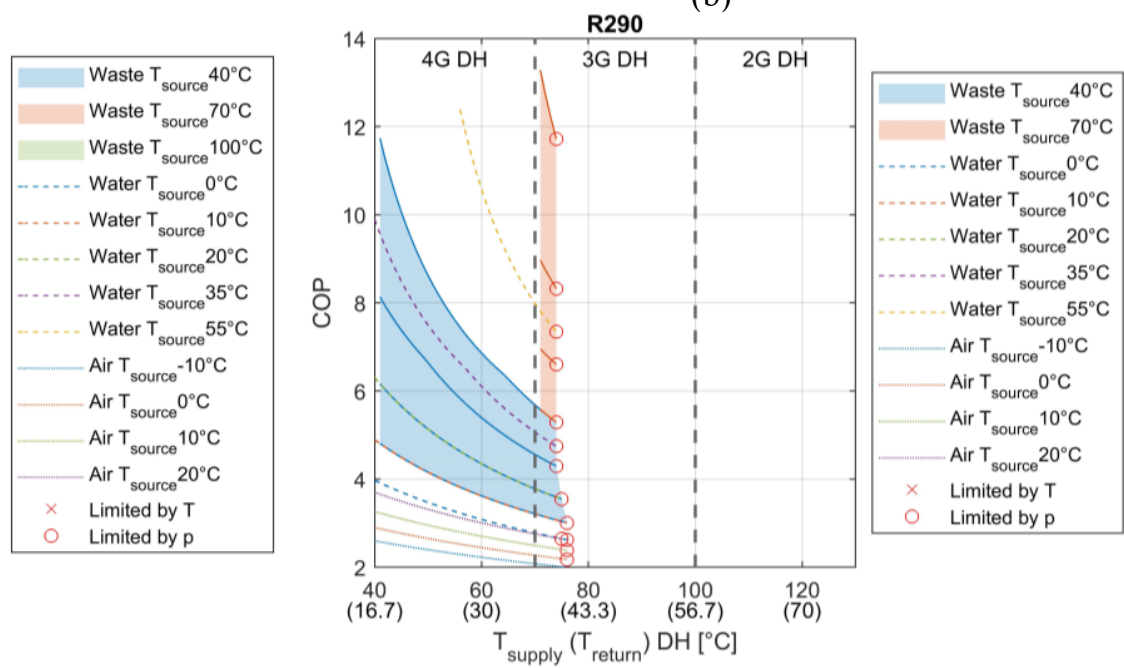

(d)

Fig. 2 COP trends for the considered fluids in the investigated scenarios, thermal levels proper of $2^{\text {nd }}, 3^{\text {rd }}$ and $4^{\text {th }}$ generation are shown in the figures

account the increase of efficiency at lower return temperature thanks to the flue gas latent heat potential exploitation [19].

\section{Results}

For the present Techno Economic Analysis, the heat pump operating hours and capacity (i.e. nominal thermal output) was assumed to be $6000 \mathrm{~h}$ and $1000 \mathrm{~kW}$, respectively.

All the investigated scenarios are well described in the Section 2, they consist of three different heat sources, each of them characterized by different thermal level $\mathrm{T}_{\text {source }}$ and temperature drop $\Delta \mathrm{T}_{\text {source. }}$ Supply and return DH temperature, on the $\mathrm{x}$-axis, are correlated by Equation 2.

Figure 2 shows the COP plotted against the district heating temperature level, decreasing monotonically as expected. Very high values are theoretically achievable when the temperature lift between the heat source and the supply water is reduced. In practise, when the available heat source temperature is higher than the $\mathrm{DH}$ return temperature, a direct heat exchange is preferrable. The COP is mainly dependent on these temperature levels, while considering the same conditions slight differences in performance among heat pumps driven by different fluids exist.

HPs exploiting air as source show different trends and lower values, this is caused by the parasitc electric power to run the fans at the evaporator heat exchanger.

The COP decreases as the temperature drop at the evaporator's source side (i.e. $\Delta T_{\text {source }}$ ) increases, since it leads to a lower pressure level on the refrigerant side. For the waste heat source, the area between the two extreme curve, relative to $10 \mathrm{~K}$ and $40 \mathrm{~K}$ temperature drop at the evaporator respectively, has been highlighted.

It is very interesting to observe how the real applicability of each fluid is limited by the constrains on the maximum temperature and pressure. R134a (Fig.2a) is limited to supply temperatures lower than $90^{\circ} \mathrm{C}$ since a higher temperature would imply an exceedance of the 
limit pressure of 28 bar. R717 (Fig. 2b) is strongly limited by the high temperature at the compressor discharge that easily goes over $180^{\circ} \mathrm{C}$ if the heat source

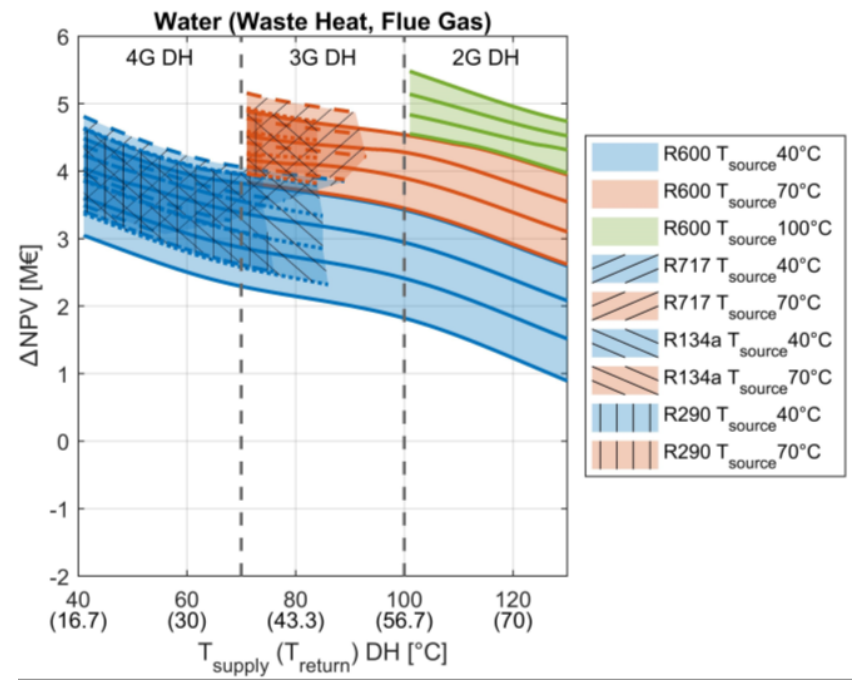

(a) temperature decreases or the $\Delta \mathrm{T}_{\text {source }}$ increases. In fact, a lower pressure at the compressor inlet causes a higher temperature at the discharge for the same pressure level
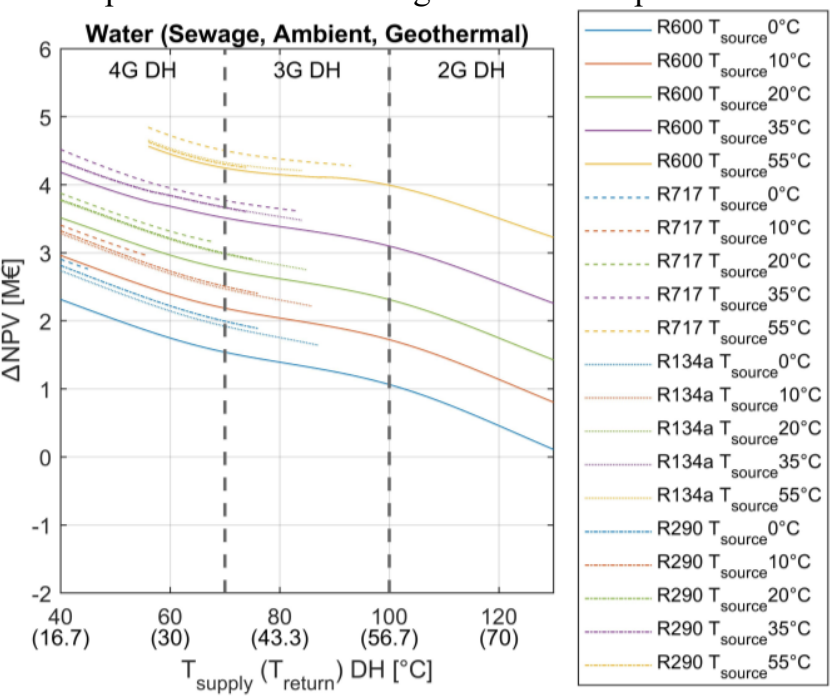

(b)

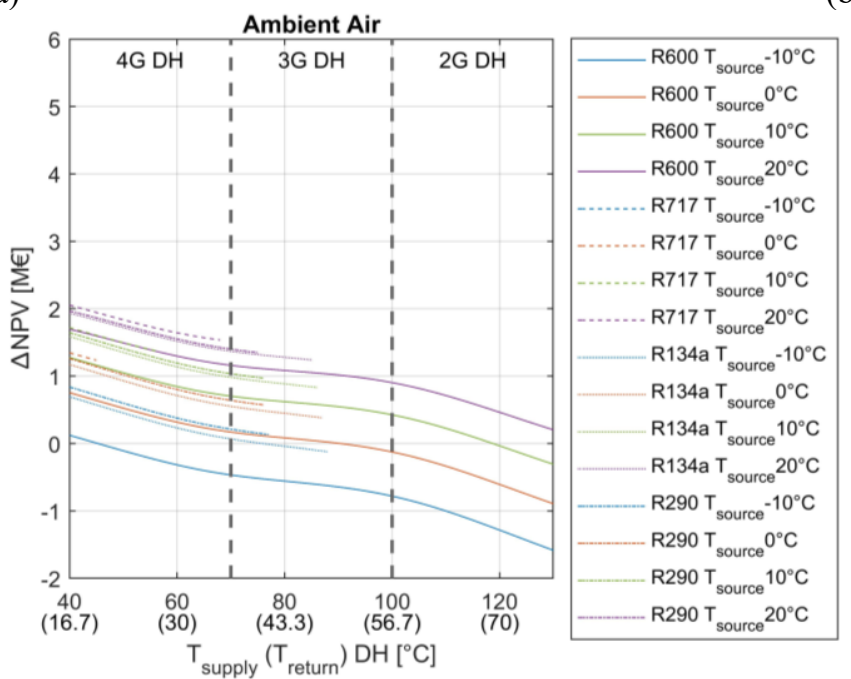

(c)

Fig. $3 \triangle \mathrm{NPV}$ trends for the considered heat source in the investigated scenarios

at the condenser. Anyway, also the pressure constrain poses a limit to the supply temperature that cannot exceed $95^{\circ} \mathrm{C}$. Consequently, as well for R134a, heat sources at $100^{\circ} \mathrm{C}$ are not exploitable.

Looking at the hydrocarbon fluid, R600 present the widest domain of applicability, thanks to the ability to reach high temperatures at relatively low pressure, on the other hand R290 is strongly limited by the maximum pressure, and it is not able to provide heat at temperatures higher than $77^{\circ} \mathrm{C}$.

Figure 2 clearly highlights how only R600, among the considered fluids, is suitable for second generation district heating, while all of them are applicable in modern networks operating at lower thermal level.

Figure 3 shows the dependency of the HP profitability with respect to an existing $\mathrm{HOB}$, as well the COP: both decrease with an increase of the DH thermal level, due to the fact that a lower COP causes a more expensive heat production. In a similar way, $\triangle \mathrm{NPV}$ is negatively affected by a decrement of the heat source temperature or by an increment of $\Delta \mathrm{T}_{\text {source. }}$
Consequently, the highest values are achieved for waste heat sourced HP, while the advantages on the HOB are limited in case of air driven HP. Moreover, looking at the Fig. 3 b, it can be inferred how the temperature levels proper of geothermal sources $\left(35^{\circ} \mathrm{C}\right.$ and $\left.55^{\circ} \mathrm{C}\right)$ result to be more profitable than those that are typical of sewage or ambient water. Non-linearities in the trend are mainly caused by the non-linear HOB efficiency with the DH return temperature, since the flue gas exploitable latent heat is not linearly dependent on the temperature.

Also the Total Capital Investment directly influences the $\triangle \mathrm{NPV}$ : in fact, fluids requiring lower volumetric mass flow of refrigerant per unit of heat exchanged allow to downsize the compressor saving a considerable amount of money.

It is important to remark that the present analysis doesn't account the cost of withdrawing the heat from the original source to the HP evaporator. This is not negligible, in particular to canalize ambient water and geothermal sources or to recover waste heat or flue gas by means of additional heat exchanger and piping. However, this cost is highly site-dependent and is out of 
the scope of this paper: it should be subtracted to the values reported in Fig.3 to get a final figure.

R717, within its domain of applicability, always results to be the most profitable option. R134a and R290 present very similar results, with the R290 slightly more profitable for HP operating with low temperature heat source. Despite the R600 is the most versatile fluid, when compared against the others, it presents the lowest $\triangle \mathrm{NPV}$, this gap in profitability is higher the lower is the temperature levels of the heat source (e.g. in the Fig. 3b, the difference between the R600 - continuous line - and the R134a and R290 - dashed lines - is considerable at $0^{\circ} \mathrm{C}$ while $\mathrm{R} 600$ is almost competitive with $\mathrm{R} 290$ at $\left.55^{\circ} \mathrm{C}\right)$.

It is possible to conclude that, among the considered alternative to environmentally harmful R134a, R717 is the preferable option, when applicable, with better performance than the R134a itself. Nevertheless, R600 demonstrates to be the most flexible fluid, applicable to different operating conditions. It is also the only one able to reach high supply temperature, thus, to replace gas-fired Heat Only Boiler in second generation district heating upgrade. Under the profitability point of view, the installation of HP in $2^{\text {nd }}$ generation DH can be more sustainable if waste heat source at temperature larger than $40^{\circ} \mathrm{C}$ could be exploited. Moreover, the ability to provide such a high temperature heat makes it a potential alternative in serving industrial utilities requiring heat at medium-low temperature, playing a key role in decarbonizing the sector. So the integration of high temperature DH system with industrial sites provide a mutual benefit.

\section{Conclusions}

The present paper explored the techno-economic potentials of three "natural fluids" (R717, R600 and R290) as low GWP alternatives to R134a for power to heat applications, assessing their economic profitability against a Heat Only Boiler.

R717, ammonia, demonstrates to be the most profitable option, when applicable, but for high supply temperature and low temperature heat sources its usage it is limited by: pressure, for heat pump components resistance, and temperature, because oil degradation imposes a constraint on the maximum compressor discharge temperature.

Within its domain of applicability, R290, propane, constitutes a viable option if non-toxic fluid usage is imposed by the context of operation, anyhow it cannot be used to supply heat at temperature higher than $75 \mathrm{C}$.

On the other hand, even if less profitable, R600, butane, is the only one to be suitable for higher temperature purposes, such as refit of $2^{\text {nd }}$ generation $\mathrm{DH}$ operating up to $120^{\circ} \mathrm{C}$ or heat supply to industrial utilities operating at that temperature level.

Moreover, R600 allows to exploit unconventional heat sources for heat pumps such as medium temperature $\left(70-100^{\circ} \mathrm{C}\right)$ waste heat. This should be taken into account within a global economic assessment, since these heat sources are typically cheap, and their exploitation allows a better exploitation of the primary energy source. Nevertheless, in case of high temperature heat source exploitation, the possibility of direct heat exchange, optionally compounded with an heat pump installation, should be carefully assessed.

\section{Acknowledgments}

This project has received funding from the European Union's Horizon 2020 research and innovation programme under Grant Agreement $\quad$ No 764706, (http://www.pumpheat.eu).

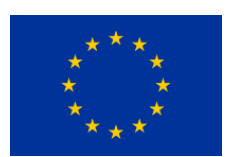

PUMP-HEAT.

\section{References}

[1] Ferrari ML, Rivatolo M, Massardo AF. Hydrogen production system from photovoltaic panels: experimental characterization and size optimization. Energy Convers Manag 2016;116:194-202.

[2] European Commission. An EU Strategy on Heating and Cooling 2016. Commun From Comm To Eur Parliam Counc Eur Econ Soc Comm Comm Reg 2016;53. https://doi.org/10.1017/CBO9781107415324.0 04.

[3] Connolly D., Mathiesen, B.V.; Østergaard PA., Möller B., Nielsen S., Lund H., Persson U., et al. Heat Roadmap Europe: Second Pre-Study. Aalborg Univ 2013.

[4] de Campos GB, Bringhenti C, Traverso A, Tomita JK. Thermoeconomic comparison between the organic flash cycle and the novel organic Rankine flash cycle (ORFC). Energy Convers Manag 2020;215:112926_1-11.

[5] David A, Mathiesen BV, Averfalk H, Werner S, Lund H. Heat Roadmap Europe: Large-scale electric heat pumps in district heating systems. Energies 2017;10:1-18. https://doi.org/10.3390/en10040578.

[6] Frate GF, Ferrari L, Desideri U. Analysis of suitability ranges of high temperature heat pump working fluids. Appl Therm Eng 2019;150:628-40. https://doi.org/10.1016/j.applthermaleng.2019. 01.034.

[7] Danish Energy Agency. Technology Data for Energy Plants for Electricity and District heating generation (v.0009 -April2020) 2016.

[8] Vannoni A, Giugno A, Sorce A. Integration of a flue gas condensing Heat Pump within a Combined Cycle: Thermodynamic, Environmental and Market assessment n.d.

[9] Sayegh; MA, Jadwiszczak; P, Axcell; BP, Niemierka; E, Bryś; K, Jouhara H. Heat pump placement, connection and operational modes in European district heating. Energy Build 2018;166:122-44.

https://doi.org/10.1016/j.enbuild.2018.02.006.

[10] Ommen T, Kj J, Brix W, Reinholdt L, Elmegaard B. Technical and economic working domains of industrial heat pumps : Part 1 e Single stage vapour compression heat 
pumps. Int J Refrig 2015;5.

[11] Jassim RK, Alhazmy MM, Zaki GM. Energy, Exergy and Thermoeconomics Analysis of Water Chiller Cooler for Gas Turbines Intake Air Cooling. Effic. Perform. Robustness Gas Turbines, 2012.

[12] Hall SG, Ahmad S, Smith R. Capital cost targets for heat exchanger networks comprising mixed materials of construction, pressure ratings and exchanger types. Comput Chem Eng 1990. https://doi.org/10.1016/00981354(90)87069-2.

[13] Bell IH, Wronski J, Quoilin S, Lemort V. Pure and Pseudo-pure Fluid Thermophysical Property Evaluation and the Open-Source Thermophysical Property Library CoolProp 2014. https://doi.org/10.1021/ie4033999.

[14] Bejan A, Tsatsaronis G, Moran M. Thermal Design and Optimization. John wiley \& Sons, Inc.; 1996.

[15] Eurostat. Energy Database 2020.

[16] Istituto Superiore per la Protezione e la Ricerca Ambientale. Tabella dei Parametri Standard Nazionali Applicabili per il Calcolo delle Emissioni per il Periodo 1 Gennaio - 31 Dicembre 20192020.

[17] The European Commission. Quarterly Report on European Electricity Markets Third Quarter of 2019. Q Rep Eur Electr Mark 2019;13.

[18] Capros P, Vita A De, Tasios N, Siskos P, Kannavou M, Petropoulos A, et al. EU Reference Scenario 2016 - A Policy Framework for Climate and Energy in the Period from 2020 to 2030. EU Ref Scenar 2016 2016:27. https://doi.org/10.2833/9127.

[19] Satyavada H, Baldi S. A novel modelling approach for condensing boilers based on hybrid dynamical systems. Machines 2016;4. https://doi.org/10.3390/machines4020010. 